\title{
Class III Obese Women's Preferences and Concerns for Cesarean Skin Incision: A Multicenter Survey
}

\author{
Marcela C. Smid, MD, MA, MS ${ }^{1}$ Rodney K. Edwards, MD, MS² Joseph R. Biggio, MD²
} Karen Dorman, MS ${ }^{1}$ Rachel C. Leduke, MSN, WHNP-BC ${ }^{2}$ Laurie L. Lesher, RN, MBA ${ }^{3}$ Tracy A. Manuck, MD ${ }^{1,3}$ George R. Saade, MD ${ }^{4}$ Ashley E. Salazar, MSN ${ }^{4}$ David M. Stamilio, MD, MSCE ${ }^{1}$ Alison M. Stuebe, MD, MSc ${ }^{1}$ Alan T.N. Tita, MD, PhD ${ }^{2}$ Caroline M. Torres, MD ${ }^{5}$ Michael W. Varner, MD ${ }^{3}$ Ronald J. Wapner, MD ${ }^{5}$

\footnotetext{
${ }^{1}$ Division of Maternal Fetal Medicine, Department of Obstetrics and Gynecology, University of North Carolina, Chapel Hill, North Carolina

2 Division of Maternal Fetal Medicine, Department of Obstetrics and Gynecology, University of Alabama at Birmingham, Birmingham, Alabama

${ }^{3}$ Division of Maternal Fetal Medicine, Department of Obstetrics and Gynecology, University of Utah, Salt Lake City, Utah

${ }^{4}$ Division of Maternal Fetal Medicine, Department of Obstetrics and Gynecology, University of Texas Medical Branch, Galveston, Texas

${ }^{5}$ Division of Maternal Fetal Medicine, Department of Obstetrics and Gynecology, Columbia University, New York, New York
}

\begin{abstract}
Address for correspondence Marcela C. Smid, MD, Division of Maternal Fetal Medicine, Department of Obstetrics and Gynecology, University of North Carolina, Chapel Hill 3010 Old Clinic Building CB\# 7516, Chapel Hill, NC 27599 (e-mail: Marcela_Smid@med.unc.edu).
\end{abstract}

\begin{abstract}
Keywords

- obesity

- cesarean delivery

- patient preference

- survey

Objective This study aims to assess class III obese women's preferences and concerns regarding cesarean delivery $(C D)$ skin incisions.

Study Design Through the National Perinatal Research Consortium (NPRC), women with body mass index $\geq 40 \mathrm{~kg} / \mathrm{m}^{2}$ at the time of enrollment completed an anonymous survey in English or Spanish. We evaluated seven domains of preferences and concerns about the cesarean skin incision.

Results We surveyed 546 women at five NPRC sites. Median age (interquartile range) was $29(25,35)$ years; $364(66 \%)$ were parous and $161(30 \%)$ had a prior CD. Women selfidentified race/ethnicity as White (31\%), non-Hispanic Black (31\%), Hispanic (31\%), other (6\%), and not reported (1\%). A total of 542 women (99\%) rated both delivering the baby in the best possible condition and decreasing incision opening/infection risk as important. Women were less likely to rate other domains as important (all $p<0.001$ ), including: having least pain possible, $n=521$ (95\%); decreasing the risk of complications in the next pregnancy, $n=490(90 \%)$; decreasing interference with breastfeeding, $n=474$ (87\%); decreasing operative time, $n=388$ (71\%); and having the least visible incision, $n=369$ (68\%).

Conclusion Women with class III obesity prioritize immediate maternal and fetal safety regarding $C D$ skin incision over other concerns including cosmetic outcome.
\end{abstract}

received

March 14, 2016

accepted after revision

July 7, 2016

published online

August 17, 2016
Copyright ( 2017 by Thieme Medical Publishers, Inc., 333 Seventh Avenue, New York, NY 10001, USA. Tel: +1(212) 584-4662.
DOI http://dx.doi.org/ 10.1055/s-0036-1586750. ISSN 0735-1631. 
The prevalence of obesity in general-and class III obesity (body mass index $[\mathrm{BMI}] \geq 40 \mathrm{~kg} / \mathrm{m}^{2}$ ) specifically-has reached epidemic proportions. In the United States, $8 \%$ of all reproductive age women have a BMI $\geq 40 \mathrm{~kg} / \mathrm{m}^{2}$, including $7 \%$ of White women, $18 \%$ of Black women, and $6 \%$ of Hispanic women. ${ }^{1}$ The prevalence of obesity in women of reproductive age has doubled in the past two decades. ${ }^{2}$ Current epidemiological projections anticipate that the prevalence of obesity will continue to increase. ${ }^{3}$

The implications of this epidemic for the care of pregnant women are far reaching. Class III obesity is a well-recognized independent risk factor for cesarean delivery (CD) ${ }^{4-6}$ Class III obese nulliparous women are three to four times more likely to undergo $\mathrm{CD}$ compared with normal weight women, ${ }^{5,7}$ and more than half of multiparous women with class III obesity attempting a vaginal birth after a CD will go on to have a repeat $\mathrm{CD}^{8}{ }^{8}$ Obesity increases the risk of $\mathrm{CD}$ complications, including vertical hysterotomy, ${ }^{9}$ postoperative wound infections, ${ }^{10,11}$ thromboembolism, ${ }^{12}$ and decreased fetal cord blood $\mathrm{pH}$ at the time of delivery. ${ }^{13}$ There is considerable debate in the obstetric literature regarding the safest type of CD skin incision for women with class III obesity. ${ }^{14,15}$ However, there is a paucity of information regarding class III obese women's preferences regarding $C D$ skin incision. The optimal practice of evidence-based medicine includes an understanding of patient preferences, expectations, and goals for health. ${ }^{16,17}$ The purpose of this survey was to better understand class III obese women's perceptions and priorities regarding $C D$ skin incision to inform clinical care and interventional studies. We also assessed the women's willingness to participate in a randomized controlled trial (RCT) of skin incision for the $\mathrm{CD}$. We hypothesized that women with class III obesity are more concerned about the safety of skin incision for themselves and their fetus than cosmetic results.

\section{Material and Methods}

We conducted an anonymous survey of women with a BMI $\geq 40 \mathrm{~kg} / \mathrm{m}^{2}$ presenting for prenatal care. We surveyed women at five tertiary referral centers belonging to the National Perinatal Research Consortium (NPRC), a collaborative effort between the University of North Carolina, University of Alabama at Birmingham, Columbia University, University of Texas Medical Branch, and the University of Utah. After initial approval at the University of North Carolina-Chapel Hill, the institutional review boards at the other four sites approved this study. Each center provides a wide scope of prenatal services and serves as a referral site for women with high-risk pregnancies. Depending on the center, approximately 10 to $30 \%$ of the eligible patient population is primarily Spanish speaking.

Research staff screened prenatal charts and approached eligible women. Women were eligible for participation if they had a BMI $\geq 40 \mathrm{~kg} / \mathrm{m}^{2}$, based on height and weight recorded in the clinical chart, and were able to read English or Spanish sufficiently well to complete the survey. Women were not approached for participation if they primarily spoke a language other than English or Spanish, could not read English or Spanish, or had a BMI $<40 \mathrm{~kg} / \mathrm{m}^{2}$ at enrollment.
Research staff reviewed clinical charts and screened eligible participants. Anonymous surveys were distributed and collected by the research staff to eligible women only. As part of the questionnaire, women were asked to self-report their height and most recent weight. We did not collect the enrollment BMI. Self-reported height and weight were used to calculate BMI described in this article, however, all women, regardless of their self-reported BMI, had an actual enrollment $\mathrm{BMI} \geq 40 \mathrm{~kg} / \mathrm{m}^{2}$ at the time of survey completion. A questionnaire using a five-point Likert scale was developed. Seven domains were assessed, including: having the least visible scar, having the least pain after the operation, decreasing how long the operation lasts, decreasing the risk that the incision opens or gets infected, not interfering with breastfeeding, decreasing risk of complications in the next pregnancy, and delivering the baby in the best condition possible. Respondents could mark the following choices: important, somewhat important, no opinion, not very important, not at all important. An optional write-in space was available for any further comments or concerns regarding skin incision. Participant comments were analyzed and grouped into themes by one author (M. C. S.) and reviewed for agreement by a second author (R. K. E.). Disagreements of thematic concentration were discussed and reviewed by the entire group until consensus was achieved. Other items in the survey included information on self-report of age, height and weight, race/ethnicity, parity, and number of the previous CDs. We include the survey as a supplementary online file (available in the online version).

Survey data were analyzed using chi-square or Fisher exact tests, as appropriate. For the purposes of this analysis, we combined "important" and "somewhat important" as one response and combined "not very important" and "not at all important" into one response. We reviewed women's "writein" comments for main themes not captured in the seven domains.

\section{Results}

From April to September 2014, 546 women completed the questionnaire, 90\% in English, and 10\% in Spanish. Of the 575 women approached for participation, 95\% completed the survey. - Table 1 displays patient characteristics. The median (interquartile range) BMI calculated from self-reported height and weight was $43 \mathrm{~kg} / \mathrm{m}^{2}$ (40.6, 46.7). Of note, while all women in this study had an actual BMI $\geq 40 \mathrm{~kg} / \mathrm{m}^{2}$ at enrollment, $17 \%$ of the women in this study self-reported a BMI $<40 \mathrm{~kg} / \mathrm{m}^{2}$.

Nearly all women rated the risk of wound infection and safety of baby as important. Compared with these two domains, women were less likely to report the other domains as important (all $p<0.0001$ ). We compared other domains to the risk of wound infection and safety of baby as these two domains were rated as most important among our respondents. Other domains in decreasing order of frequency included: decreasing the risk of complications in the next pregnancy, decreasing interference with breastfeeding, decreasing operative time, and having the least visible incisionsee -Table 2. 
Table 1 Participant characteristics

\begin{tabular}{|c|c|}
\hline Characteristics & $N=546$ \\
\hline \multicolumn{2}{|l|}{ Age (y) } \\
\hline$<20$ & $18(3)$ \\
\hline $20-34$ & $384(71)$ \\
\hline$\geq 35$ & $138(25)$ \\
\hline Missing & $6(1)$ \\
\hline Nulliparous & $184(34)$ \\
\hline Missing & $7(1)$ \\
\hline \multicolumn{2}{|c|}{ Prior cesarean deliveries } \\
\hline 0 & $379(69)$ \\
\hline$\geq 1$ & $170(30)$ \\
\hline Missing & $6(1)$ \\
\hline \multicolumn{2}{|c|}{ Prior vaginal deliveries } \\
\hline 0 & $296(54)$ \\
\hline$\geq 1$ & $250(45)$ \\
\hline Missing & $8(1)$ \\
\hline \multicolumn{2}{|l|}{ Race/ethnicity } \\
\hline White & $170(31)$ \\
\hline Black & $171(31)$ \\
\hline Hispanic & $171(31)$ \\
\hline Other & $28(6)$ \\
\hline Missing & $6(1)$ \\
\hline \multicolumn{2}{|l|}{ Language } \\
\hline English & $494(90)$ \\
\hline Spanish & $54(10)$ \\
\hline
\end{tabular}

Note: Data are presented as $n(\%)$.

There were significant differences in maternal characteristics related to responses for four domains: having the least pain, decreasing interference with breastfeeding, having the least visible scar, and decreasing complications in the next pregnancy. Nulliparous women $(n=172 ; 93 \%)$ were less likely to rate least pain as important compared with multipa- rous women $(n=341 ; 96 \%)(p=0.005)$. More nulliparous women rated decreasing complications in the next pregnancy as important compared with multiparous women (93 vs. $88 \%$; $p=0.01)$. Black women $(n=139 ; 81 \%)$ were less likely to rate decreasing interference with breastfeeding as important compared with white $(n=150 ; 88 \%)$, Hispanic $(n=151$; $89 \%)$, or women self-reporting race/ethnicity as "other" $(n=27 ; \quad 96 \%) \quad(p=0.04) . \quad$ Spanish-speaking women ( $n=53,98 \%)$ were also more likely to rate decreasing interference with breastfeeding as important compared with English-speaking women $(n=419 ; 85 \%)(p=0.03)$. Black women $(n=131 ; 77 \%, p<0.0001)$ and Hispanic women ( $n=126 ; 74 \%, p<0.0001)$ were more likely than White women $(n=89 ; 53 \%)$ to report that the least visible scar is important. Desire for least visible scar did not differ by BMI $(p=0.12)$, prior $\mathrm{CD}(p=0.18)$, or language preference $(p=0.29)$. There were no differences in preference in responses among women with and without a prior CD (all $p \geq 0.05$ ), except for interference with breastfeeding (80 vs. $90 \%, p=0.01$ ).

A total of 116 women (21\%) submitted optional "write-in" comments regarding the $\mathrm{CD}$. Of these $17(15 \%)$ women specifically mentioned that they desired a "bikini" or transverse skin incision. The majority of comments provided clarification on the seven themes assessed in the survey questions. However, women described an additional seven themes: least time in the hospital, ease of postoperative care, individualization, operative technique, requesting more information/own research, and impact on the ability to attempt a vaginal birth after cesarean (VBAC) in the next pregnancy. Women's concerns regarding VBAC were the most frequent domain mentioned, and it is evident that many women do not differentiate between the skin and uterine incision (-Table 3).

With regard to willingness to participate in a RCT of CD skin incision, women 20 to 34 years old were more likely to report willingness to participate than women aged $\geq 35$ or $<20$ $(p=0.006)$. Black (28\%) and Hispanic (32\%) women were also more likely to report a willingness to participate than White (18\%) and other women (14\%) $(p<0.0001)$. Of the women surveyed, 141 (26\%) agreed that they would participate in an RCT of CD skin incision, and 194 (35\%) were unsure if they would participate.

Table 2 Survey responses

\begin{tabular}{|l|l|l|l|l|l|}
\hline Domain & Important & No opinion & Not important & No response & $p$ Value \\
\hline Decreasing risk of incision opening or infection & $542(99.3)$ & $1(0.2)$ & $3(0.6)$ & - & Reference \\
\hline Deliver baby in best condition possible & $542(99.3)$ & $2(0.35)$ & $2(0.35)$ & - & $>0.99$ \\
\hline Having least pain & $519(95.0)$ & $9(1.7)$ & $18(3.3)$ & - & $<0.001$ \\
\hline Decreasing risk of complication in next pregnancy & $488(89.4)$ & $28(5.1)$ & $27(4.9)$ & $3(0.6)$ & $<0.001$ \\
\hline Decreasing interference with breastfeeding & $472(86.5)$ & $43(7.8)$ & $30(5.5)$ & $1(0.2)$ & $<0.001$ \\
\hline Decreasing operative time & $387(70.9)$ & $85(15.5)$ & $71(13.0)$ & $3(0.5)$ & $<0.001$ \\
\hline Least visible & $367(67.2)$ & $40(7.3)$ & $139(25.5)$ & - & $<0.001$ \\
\hline
\end{tabular}

Note: Data are presented as $n$ (\%). The $p$ values represent chi-square comparisons of proportion of women answering "important," “no opinion," "not important," and "no response" compared with the reference-responses for risk of infection. 
292 Class III Obesity on Women's Preferences for Cesarean Skin Incision Smid et al.

Table 3 Main themes of write in comments

\begin{tabular}{|c|c|}
\hline Theme & Representative quotes \\
\hline Recovery time & $\begin{array}{l}\text { "That it would not interfere with me being able to take care of the baby once we } \\
\text { return home" }\end{array}$ \\
\hline \multirow[t]{3}{*}{ VBAC/uterine incision } & $\begin{array}{l}\text { "Whatever is safest for baby and I, and gives me the best chance for VBAC for } \\
\text { any future births" }\end{array}$ \\
\hline & $\begin{array}{l}\text { "How does the uterus heal from being cut different ways, importance of VBAC } \\
\text { education for next baby" }\end{array}$ \\
\hline & $\begin{array}{l}\text { "Bikini cut or transverse scar leaves a minimal risk for future VBACs whereas the } \\
\text { vertical incision T-incision and J-incision all lead to higher risks for VBACs } \\
\text { through uterine rupture and to scar at maximum is } 1.9 \% \text { without induction } \\
\text { according to the ACOG" }\end{array}$ \\
\hline \multirow[t]{3}{*}{ Postoperative care } & "The cleaning and treating after left the hospital" \\
\hline & $\begin{array}{l}\text { "To make sure we talk about how to clean the incision to keep it from getting to } \\
\text { be a big problem" }\end{array}$ \\
\hline & "Reducing drainage, swelling, that it is easy to care for at home postop" \\
\hline \multirow[t]{2}{*}{ Individualization } & "The way you are closed up depending on the size of the female" \\
\hline & $\begin{array}{l}\text { "Incision type based on individual patient. For a larger woman a vertical } \\
\text { incision, in my opinion, would heal better" }\end{array}$ \\
\hline \multirow[t]{4}{*}{ Operative technique } & "It more worries me about how roughly they pull the baby out" \\
\hline & "Cut gently, handle tissue gently" \\
\hline & “Do not use staples” \\
\hline & $\begin{array}{l}\text { "Type/method used to close the incision, that is, staples, stitched that have to } \\
\text { be removed, dissolvable stiches" }\end{array}$ \\
\hline \multirow[t]{2}{*}{ Requesting more information/own research } & $\begin{array}{l}\text { "I'd want to know more research on pros/cons of the different incisions and } \\
\text { make it myself. From my research, bikini seems to always be best in almost any } \\
\text { size woman depending on anatomy" }\end{array}$ \\
\hline & "Due to excess skin what would be the risk with a transverse" \\
\hline \multirow[t]{2}{*}{ Prior scar } & $\begin{array}{l}\text { "I already had a cesarean delivery with a transverse incision and the recuper- } \\
\text { ation went very well. For this pregnancy I would like to have the same" }\end{array}$ \\
\hline & $\begin{array}{l}\text { "I had two up and down due to emergencies for me it has to do with the best for } \\
\text { my child. Up and down is not a scar that is not always nice looking but when you } \\
\text { look at your child its all worth it. It's not all about vanity to me" }\end{array}$ \\
\hline
\end{tabular}

Abbreviations: ACOG, the American Congress of Obstetricians and Gynecologists; post-op, postoperative; VBAC, vaginal birth after cesarean.

\section{Comment}

The results of our survey demonstrate that pregnant women with class III obesity are highly invested in their own safety and that of their fetus. Above all else, they desire the safest approach to $C D$ skin incision.

Despite women's desire for the safest CD skin incision, providers cannot definitely provide a consistent evidencebased answer to which type of skin incision is, in fact, the safest for women with class III obesity. There are numerous studies, none of which are RCTs, which have assessed the risks associated with the type of skin incision among obese pregnant women undergoing CD. Results are varied, with four studies indicating an increased risk of wound complication with vertical skin incision, ${ }^{10,18-20}$ four studies showing no difference in complications based on incision type, ${ }^{11,21-23}$ and one study indicating vertical skin incision having a lower risk of wound complication. ${ }^{15}$ There is even less information regarding which incision type maximizes fetal safety. Ed- wards et al (2013) demonstrated that among women with class II or III obesity, a transverse abdominal incision, compared with a vertical incision, is associated with a 3.4 relative risk (95\% confidence interval: $1.56-7.42)$ of an umbilical base deficit $12 \mathrm{mmol} / \mathrm{L}$ or more. ${ }^{13}$ Thus, while women with class III obesity are at high risk of $C D$, obstetricians and women are indeed left in an evidence-conflicted zone with regard to safest skin incision. There is one single center RCT currently underway that aims to assess wound complication rates with vertical compared with Pfannenstiel incisions among women with $\quad$ BMI $\geq 40 \quad \mathrm{~kg} / \mathrm{m}^{2} \quad$ (Clinicaltrials.gov identifier NCT01897376). While we eagerly await the results of this RCT, we suggest that there may be continued equipoise regarding the maternal and neonatal risks, other than wound complication, associated with CD skin incisions.

Shared decision-making is now frequently used in health care as a means to achieve improved patient satisfaction and outcomes. $^{24,25}$ Obese pregnant women are less likely than nonobese pregnant women to verbalize opinions for fear of 
Table 4 Recommended approach for discussion of CD for women with class III obesity

\begin{tabular}{|l|}
\hline - Elicit women's concerns and preferences about CD and operative technique \\
\hline - Discuss increased risk of CD for women with Class III obesity during prenatal care \\
\hline - Describe the difference between skin and uterine incisions at the time of CD \\
\hline - Review risks, benefits, and unknowns about safety of skin incision techniques for maternal and fetal outcomes \\
\hline - Review risks and benefits of uterine incisions in current and future pregnancies \\
\hline - Discuss plan for skin closure technique \\
\hline - Discuss implications of various techniques for skin and uterine incision on options for delivery route in next pregnancy \\
\hline - Review postoperative care, including possibility of frequent visits if wound complication arises \\
\hline
\end{tabular}

Abbreviation: $C D$, cesarean delivery.

stigmatization and humiliation by health care providers and a perception of depersonalized care as a result of their obesity. ${ }^{26-28}$ Numerous studies have demonstrated the importance of CD in women's understanding of themselves, their bodies and their birth experience. ${ }^{29-31}$ In qualitative studies, women undergoing $\mathrm{CD}$ report as particularly disturbing the lack of communication with the medical team during the $C D$ and a perceived loss of individualized care, as their personal birth experience was replaced with a highly medicalized procedure. $^{29}$ The women interviewed after an emergency CD echo this sentiment: lack of control and communication is highly traumatic. ${ }^{32}$ In a nationwide survey, obstetric providers reported preferentially using Pfannenstiel over vertical abdominal incisions for $\mathrm{CD}$ of pregnant women with class III obesity, and patient preference was not an important factor in physicians' decision-making regarding the type of the abdominal incision. ${ }^{33}$

The main strength of this study is that we employed a multicenter approach to eliciting the preferences and concerns of women with class III obesity. We anticipate that this survey will help us better plan a multicenter RCT of skin incision. Based on the results of this survey, if we enrolled $80 \%$ of women who strongly agreed or agreed that they would participate in an RCT and 30\% of patients who were unsure, we project that we would be able to enroll $31 \%$ of eligible women at NPRC sites into an RCT of CD skin incision.

Limitations of this study include that our five sites are all referral centers for women with complicated pregnancies. Therefore, the results of this survey may not be generalizable to all practice settings. Despite all women in the study having an actual BMI $\geq 40 \mathrm{~kg} / \mathrm{m}^{2}$, almost one-fifth of our participants self-reported a BMI of $<40 \mathrm{~kg} / \mathrm{m}^{2}$. Because the surveys were anonymous and BMI at enrollment was not collected, we were unable to correlate enrollment and self-reported BMI. While this may be viewed as a limitation, it also serves to provide insight that a substantial number of pregnant women with class III obesity, in fact, do not report a height and/or weight consistent with their enrollment BMI and possibly view themselves as less significantly obese than they are. We did not have a comparison group of women without class III obesity. While women with BMI $<40 \mathrm{~kg} / \mathrm{m}^{2}$ may have similar preferences and concerns for $C D$ incision, the debate in the literature regarding which is the least morbid skin incision for
CD focuses primarily on the most obese women, since they have the highest risk of $\mathrm{CD}$ complications and a Pfannenstiel or other low-transverse skin incision is favored in nonobese women and women with lesser obesity. ${ }^{10,11,15}$

Until more definitive studies are available regarding the comparative safety of various skin incisions among pregnant obese women, we suggest that providers discuss CD skin incision options with patients, including areas of uncertainty; to lead to shared decision-making between a woman and her provider. We outline recommendations for important discussion points regarding $\mathrm{CD}$ for clinicians counseling women with class III obesity ( - Table 4). Our study also reveals that there may be a misconception among women regarding the difference between the skin and uterine incisions and the implications on maternal and fetal outcomes in the current and subsequent pregnancies. Eliciting a woman's concerns and priorities regarding her incision may allow for a joint decision that maximizes safety, and improves patient satisfaction.

Conflict of Interest

None.

\section{Acknowledgments}

The authors would like to thank the research staff at the various institutions in the National Perinatal Research Consortium for their efforts and the participating patients for their time providing responses to the survey. They would also like to thank Alexis Panzer for her assistance in data entry. Alexis Panzer is a medical student at the University of North Carolina-Chapel Hill. She was not compensated for her work and she volunteered to assist in the study.

\section{References}

1 Flegal KM, Carroll MD, Kit BK, Ogden CL. Prevalence of obesity and trends in the distribution of body mass index among US adults, 1999-2010. JAMA 2012;307(5):491-497

2 Ogden CL, Carroll MD, Curtin LR, McDowell MA, Tabak CJ, Flegal KM. Prevalence of overweight and obesity in the United States, 1999-2004. JAMA 2006;295(13):1549-1555 
3 Wang Y, Beydoun MA, Liang L, Caballero B, Kumanyika SK. Will all Americans become overweight or obese? estimating the progression and cost of the US obesity epidemic. Obesity (Silver Spring) 2008;16(10):2323-2330

4 Stotland NE, Hopkins LM, Caughey AB. Gestational weight gain, macrosomia, and risk of cesarean birth in nondiabetic nulliparas. Obstet Gynecol 2004;104(4):671-677

5 Crane JM, Murphy P, Burrage L, Hutchens D. Maternal and perinatal outcomes of extreme obesity in pregnancy. J Obstet Gynaecol Can 2013;35(7):606-611

6 Chu SY, Kim SY, Schmid CH, et al. Maternal obesity and risk of cesarean delivery: a meta-analysis. Obes Rev 2007;8(5):385-394

7 Kominiarek MA, Vanveldhuisen P, Hibbard J, et al; Consortium on Safe Labor. The maternal body mass index: a strong association with delivery route. Am J Obstet Gynecol 2010;203(3):264. e1-264.e7

8 Kominiarek MA, Zhang J, Vanveldhuisen P, Troendle J, Beaver J, Hibbard JU. Contemporary labor patterns: the impact of maternal body mass index. Am J Obstet Gynecol 2011;205(3):244.e1-244.e8

9 Brocato BE, Thorpe EM Jr, Gomez LM, Wan JY, Mari G. The effect of cesarean delivery skin incision approach in morbidly obese women on the rate of classical hysterotomy. J Pregnancy 2013; 2013:890296. Doi: 10.1155/2013/890296

10 Smid MC, Kearney MS, Stamilio DM. Extreme obesity and postcesarean wound complications in the maternal-fetal medicine unit cesarean registry. Am J Perinatol 2015;32(14):1336-1341

11 Stamilio DM, Scifres CM. Extreme obesity and postcesarean maternal complications. Obstet Gynecol 2014;124(2 Pt 1):227-232

12 Robinson HE, O'Connell CM, Joseph KS, McLeod NL. Maternal outcomes in pregnancies complicated by obesity. Obstet Gynecol 2005;106(6):1357-1364

13 Edwards RK, Cantu J, Cliver S, Biggio JR Jr, Owen J, Tita AT. The association of maternal obesity with fetal $\mathrm{pH}$ and base deficit at cesarean delivery. Obstet Gynecol 2013;122(2 Pt 1):262-267

14 Alanis MC, Goodnight WH, Hill EG, Robinson CJ, Villers MS, Johnson DD. Maternal super-obesity (body mass index $>$ or $=$ 50) and adverse pregnancy outcomes. Acta Obstet Gynecol Scand 2010;89(7):924-930

15 Marrs CC, Moussa HN, Sibai BM, Blackwell SC. The relationship between primary cesarean delivery skin incision type and wound complications in women with morbid obesity. Am J Obstet Gynecol 2014;210(4):319.e1-319.e4

16 Montori VM, Brito JP, Murad MH. The optimal practice of evidencebased medicine: incorporating patient preferences in practice guidelines. JAMA 2013;310(23):2503-2504

17 van der Weijden T, Pieterse AH, Koelewijn-van Loon MS, et al. How can clinical practice guidelines be adapted to facilitate shared decision making? A qualitative key-informant study. BMJ Qual Saf 2013;22(10):855-863
18 Wall PD, Deucy EE, Glantz JC, Pressman EK. Vertical skin incisions and wound complications in the obese parturient. Obstet Gynecol 2003;102(5 Pt 1):952-956

19 Alanis MC, Villers MS, Law TL, Steadman EM, Robinson CJ. Complications of cesarean delivery in the massively obese parturient. Am J Obstet Gynecol 2010;203(3):271.e1-271.e7

20 Thornburg LL, Linder MA, Durie DE, Walker B, Pressman EK, Glantz JC. Risk factors for wound complications in morbidly obese women undergoing primary cesarean delivery. J Matern Fetal Neonatal Med 2012;25(9):1544-1548

21 McLean M, Hines R, Polinkovsky M, Stuebe A, Thorp J, Strauss R. Type of skin incision and wound complications in the obese parturient. Am J Perinatol 2012;29(4):301-306

22 Bell J, Bell S, Vahratian A, Awonuga AO. Abdominal surgical incisions and perioperative morbidity among morbidly obese women undergoing cesarean delivery. Eur J Obstet Gynecol Reprod Biol 2011;154(1):16-19

23 Vermillion ST, Lamoutte C, Soper DE, Verdeja A. Wound infection after cesarean: effect of subcutaneous tissue thickness. Obstet Gynecol 2000;95(6 Pt 1):923-926

24 Barry MJ, Edgman-Levitan S. Shared decision making-pinnacle of patient-centered care. N Engl J Med 2012;366(9):780-781

25 Joosten EA, DeFuentes-Merillas L, de Weert GH, Sensky T, van der Staak CP, de Jong CA. Systematic review of the effects of shared decision-making on patient satisfaction, treatment adherence and health status. Psychother Psychosom 2008;77(4):219-226

26 Nyman VM, Prebensen ÅK, Flensner GE. Obese women's experiences of encounters with midwives and physicians during pregnancy and childbirth. Midwifery 2010;26(4):424-429

27 Furber CM, McGowan L. A qualitative study of the experiences of women who are obese and pregnant in the UK. Midwifery 2011; 27(4):437-444

28 Smith D, Lavender T. The maternity experience for women with a body mass index $\geq 30 \mathrm{~kg} / \mathrm{m} 2$ : a meta-synthesis. BJOG 2011; 118(7):779-789

29 Porter M, van Teijlingen E, Chi Ying Yip L, Bhattacharya S. Satisfaction with cesarean section: qualitative analysis of openended questions in a large postal survey. Birth 2007;34(2): 148-154

30 Erb L, Hill G, Houston D. A survey of parents' attitudes toward their cesarean births in Manitoba hospitals. Birth 1983;10(2):85-92

31 Green JM, Baston HA. Feeling in control during labor: concepts, correlates, and consequences. Birth 2003;30(4):235-247

32 Somera MJ, Feeley N, Ciofani L. Women's experience of an emergency caesarean birth. J Clin Nurs 2010;19(19-20):2824-2831

33 Smid MC, Smiley SG, Schulkin J, et al. The problem of the pannus: physician preference survey and a review of the literature on cesarean skin incision in morbidly obese women. Am J Perinatol 2016;33(5):463-472 